\title{
A Review on Leisure City Evaluation Index Systems and Model
}

\author{
Hongyu Lian, Peiyu Yue \\ School of Tourism and Culture Industry \\ Chengdu University \\ Chengdu 610106
}

\begin{abstract}
Alongside the development of social civilization and the transformation of urban structure, much more emphasis has been put on the level of urban leisure development and the construction of leisure cities. From the perspectives of the definition of Leisure City, evaluation index system construction, evaluation model and method, this paper combs the research achievements of evaluation index system and model of Leisure City, to reflect the development and evaluation of Leisure City in a comprehensive way. It provides the reference for the corresponding academic research and policy making regarding urban development.
\end{abstract}

Keywords-Leisure City; evaluation index system; review; model

\section{INTRODUCTION}

Leisure is considered as the first driving force for social and economic development in the 21st century, while urban leisure is a new form of urban development in the post-industrial era in developed countries [1]. The transformation of urban economic structure raises people's happiness index and alleviates the pressure of our living environment. Under this circumstance, the emergence and development of leisure cities become more and more important [2]. It happens that the development of Leisure City coincides with the goals of the Scientific Outlook on Development, namely, caring people, urban economy, sustainability and harmony, and has a very close relationship with the scientific development of the city [3]. From the perspectives of the definition of Leisure City, evaluation index system construction, evaluation model and method, this paper combs the research achievements of Leisure City evaluation index system and model, to reflect the development and evaluation of Leisure City in a comprehensive way. It provides the reference for the corresponding academic research and policy making regarding urban development.

\section{THE DEFINITION OF LEISURE CITY AND ITS RESEARCH PERSPECTIVES}

Foreign scholars have studied the Leisure City since the 1960s. The studies, mainly from the perspective of geography,

Funds: 1.Chengdu soft science research project (2017-RK00-00189-ZF): Research on Evaluation Model and Development Path of the Leisure City in Chengdu;

2. Chengdu philosophy and social science planning project (2018R22): Research on the Construction of Public Leisure Service System and the Improvement of Residents' Sense of Gain in Chengdu;

3. Sichuan Grassroots Cultural Service Research Center Project (JY2018B03): Research on the Construction of Urban Public Leisure Service System Based on the Improvement of Sense of Gain of the Underprivileged. focus on urban planning, function division, leisure action, regional tourism planning, urban group behavior and special crowd behavior. Some center on the topic how urban leisure development further accelerates the speed of urban space reconstruction. To be specific, how does the characteristic of space structure of urban industrial district, commercial district and residential district change with the city urban leisure development. Foreign scholars have made researches on city recreational space on the basis of the central business district (CBD) concept [4].

Foreign scholars have studied the Leisure City since the 1960s. The studies, mainly from the perspective of geography, focus on urban planning, function division, leisure action, regional tourism planning, urban group behavior and special crowd behavior. Some center on the topic how urban leisure development further accelerates the speed of urban space reconstruction. To be specific, how does the characteristic of space structure of urban industrial district, commercial district and residential district change with the city urban leisure development. Foreign scholars have made researches on city recreational space on the basis of central business district (CBD) concept

The number of researches on Leisure City in China rises with the advance of urban construction. Scholars like Wang Xuefeng (2003) [5], ShanYuanYuan (2005) [6], Xu Minghong (2006) [7], Wei Xiaoan (2007) [8] have proposed the definitions of the Leisure City. Form the aspects of urban construction, residents' consumption and economic development, they have pointed out the decisive influence of entertainment resources, recreational function, and recreational environment on the leisure nature of the urban. They also put forward that the main body of the Leisure City should contain both urban residents and tourists. The city needs to be livable, possesses the humanistic spirit to welcome visitors and promote the harmonious co-exist of tourism activities and local residents' leisure activities.

Lu Ning (2011) sorted out the definition of Leisure City from different perspectives. From the perspective of people's need, she put forward that Leisure City should center around people's leisure needs, and the Leisure City is a high-level form emerged gradually by considering people's ultimate needs and requirements for urban quality. From the perspective of urban economics, production factors are constantly concentrated in the leisure industry sector in Leisure City, and the tertiary industry with leisure subject industry as the core is 
the pillar of the city's economic development. It serves local residents' life while attracting tourists, through which realizes the diversification and branding of leisure facilities, leisure activities and leisure products, thus influencing the function and development of the city. Seen from the sustainable theory, Leisure City is a harmonious city that is suitable for living, traveling, working and playing, which integrates people with nature and society, inherits and develops urban culture, and aims at realizing environmental friendliness and ecological civilization [3].

Ren ci (2015) made a comprehensive elaboration on the relationship between Leisure City and urban recreation, as well as the characteristics and types of Leisure City. It is pointed out that recreation is the basic function of city, and city is the foothold of leisure. Leisure City boasts not only developed leisure system, but also its own recreational characteristics. In terms of characteristics, Leisure City should have superior natural environment, unique urban characteristics, strong cultural atmosphere, rich leisure products and perfect infrastructure. With regards to city types, leisure cities can be classified into city for residents, city for tourists or city mixed with both residents and tourists. From the perspective of object, namely resources, the Leisure City can be categorized into comprehensive one and functional Leisure City [9].

In general, the Leisure City itself is broadly defined from various angles. The recreational function of the city, at the macro level, is the driving force of the economy and industry, and at the micro level, is improving the living environment and quality of people's life, so the urban policy-makers come to think highly of the shaping of Leisure City.

\section{CONSTRUCTION OF LEISURE CiTY EVALUATION INDEX SYSTEM}

There are few studies on the evaluation index system of Leisure City in foreign countries. Most are concerning about the criteria establishment for assessing the level of urban leisure. For example, the election of happy valley and the best place in America mainly focuses on air quality, water quality, traffic, noise, recreational facilities, life services, interpersonal relations, population, employment rate, education, vegetation coverage, etc., with emphasis on city livability and amenity (Lv Ning, 2011) [10]. As for city leisure, foreign researches mainly shed light on the influence on city development from aspects like urban residents' leisure time and the behavior, the recreational environment, urban residents' consumption on leisure, leisure industry and leisure. Research are mainly concentrated in the following four topics: the government role in the process of urban recreation planning and action; the influence of entertainment facilities on urban growth and economic development; the relationship between entertainment environment and life satisfaction of urban residents; service objects and elements of urban leisure construction (Lou Jiajun, 2018) [11]

As for the evaluation and model construction of Leisure City, domestic scholars put forward different evaluation systems from different perspectives. Wang Xuefeng (2003) proposed a hard index system and a soft index system based on the qualification of constructing leisure cities. The former includes the indexes of urban modernization and urban internationalization, while the latter contains leisure subject, leisure object, leisure medium and other factors [5]. Zheng Shenghua and Liu Jialong (2006) studied the evaluation system of urban leisure development from statistical indicators and survey indicators, and such elements as strength system, power system, ability system and charm system [12]. Scholars like Shan Yuanyuan (2005) [6] and Cao Xinxiang (2010) [13] established an evaluation index system of Leisure City including leisure subject, leisure object and leisure medium. Li Yuejun (2007) [15] and Wang Xiaoli (2007) [14] put forward the Leisure City evaluation index and the urban leisure suitability and its evaluation objects. Chen Min (2010), on the view of leisure theory, came up with the Leisure City evaluation index system that contains subject leisure degree (frequency and satisfaction of entertainment), object leisure degree (urban economic development, leisure industry structure and leisure environment) and medium leisure degree (leisure guidance and leisure policy support) [16]. Lv Ning (2011, 2013) took the city leisure index (CLI) as the quantitative evaluation standard of Leisure City, proposed the system elements, namely, urban comprehensive strength, residents' leisure potential and urban leisure environment, and divided the classification model of Leisure City is three types, based on which figured out the models and directions for the development of the Leisure City [3-4]. Liang Feng (2013) drew on the diamond model of management competitiveness and the framework of economic supply and demand analysis to construct the index system of urban leisure environment, supporting industry, leisure supply system, leisure enterprise market structure and residential leisure demand [17]. Liu Xinrong (2007) [18], Ouyang Xinhui and Chen Jianshu (2008) [19], Lu Yong (2013)[20], Peng Weixiang and Li Yuee(2013) [21], Fang Shimin( 2016) [22] based on economics perspective, have successively built and studied evaluation index system of urban leisure economic competitiveness from the dimensions like leisure economy and culture, scale, structure, environment and growth.

In addition to the above scholars, some professional academic organizations and social institutions also pay close attention to the evaluation of Leisure City. East China Normal University Leisure Research Center places emphasis on the evaluation of urban leisure. Since 2011, it has made follow-up studies on 36 cities and published The Annual Report on China's Urban Recreationalization Development for eight consecutive years, contributing rich data and research results for the evaluation of domestic leisure cities. Scholars like Lou Jiajun, Li Limei, Fu Lixia, Hu Sang, Zhang Guanghai, Liu Jinhong, Liu Run, Lou Zhining, Wang Nan, Xu Peng and Liu Song kept on looking at the aspects of city recreationalization like the development assessment, quality measurements, evaluation system, regional differences and coordinated development. In 2007, Qiu Shi Moderate Prosperity Journal and Tongji University Golf School of Business jointly released the Chinese Leisure City selection index system which estimates the economic status, city leisure infrastructure, entertainment environment, and leisure culture and leisure satisfaction. Later in 2010, Moderate Prosperity Journal, together with Chengdu Real Estate Bureau announced the Leisure City evaluation standard system. Put forward the 
environmental leisure strength including natural environment and human environment, basic leisure strength including infrastructure and leisure facilities and core leisure strength containing citizens' entertainment capacity and satisfaction, which constitute the leisure structural system theory. In 2007, Tourhood Planning and Design Institute and Asia Pacific Center for the Study of Leisure, Zhejiang University (APCL) jointly established theoretical framework of Leisure City development, and put out the China city leisure index (CLI) that consists of LSA (Leisure index analysis) and MOA (public evaluation) at National Technical Committee for Leisure Standardization in 2010 [9]

\section{EVALUATION METHOD AND EMPIRICAL STUDY OF LEISURE CITY}

Among the existing evaluation index systems of Leisure City, some systems mainly focus on the evaluation dimension and index system at the conceptual level and quite a few systems are applied in the specific city evaluation. This part mainly reviews the evaluation system of empirical research.

The evaluation methods adopted are economic analysis, expert evaluation, data envelopment analysis, analytic hierarchy process, fuzzy evaluation method and mathematical statistics. Among them, expert evaluation and analytic hierarchy process are used frequently. In mathematical statistics, cluster analysis, discriminant analysis, principal components analysis and factor analysis are frequently used, and the principal components analysis and factor analysis have more advantages. The most often used evaluation tool is SPSS, the most authoritative statistical software used at present. In addition, some functions of EXCEL in OFFICE software are also applied in some researches [9].

From the perspective of empirical evaluation objects and evaluation results, most of the researches focus on a specific city, and some of the researches with a long period study and profound subject mainly compare multiple cities. There are many researches taking cities that are famous for leisure such as Chengdu, Hangzhou and Qingdao for study. As for the comparative study of multiple cities, Lv Ning (2009, 2013) used "leisure - comprehensive strength" model to 4 municipalities, 26 provincial capitals and 9 municipalities with independent planning status under the National Social and Economic Development [3], [23]. Cao Xinxiang (2010) conducted evaluation of urban leisure strength on 15 domestic tourist cities and famous historical and cultural cities [13]. Lou Jiajun (2011-2019) made city leisure level evaluation and index ranking on 4 municipals, 27 provincial capitals and 5 municipalities with independent planning status under the National Social and Economic Development. Wang Nan (2016) measured and analyzed the urban leisure development quality of six international cities in Asia, that is, Beijing, Shanghai, Hong Kong, Singapore, Tokyo and Seoul [24].

In general, the empirical study of the index system can help understand the development and degree of specific cities in the leisure field, and the comparative study of multiple cities can also make each city realize its own progress, characteristics and shortcomings, and also allow cities to learn from each other, providing a reference for the strategy and policy making of Leisure City construction.

\section{CONCLUSION}

To sum up, in terms of research objects, although domestic and foreign researches have done a lot in the evaluation of Leisure City, there is no research that puts forward the concept and evaluation system of the whole Leisure City. Concerning the research method and paradigm, the domestic evaluation index system of city leisure is more mature, but there are still some limitations in the evaluation content. With regard to guarantee for practice, foreign countries have more experience in ensuring the equal leisure rights of residents, which is especially worth learning for the construction and development of China's leisure cities.

\section{REFERENCE}

[1] Lou Jiajun, Xu Aiping, Ma Hongtao. The Annual Report on China's Urban Recreationalization Development (2017) [M]. Shanghai: Shanghai Jiao Tong University Press, 2018: 1 .

[2] Ye Yumin. General Outline of China's Sustainable Development China's Urbanization and Sustainable Development [M]. Beijing: Science Press, 2007: 12-25.

[3] Lv Ning. Leisure City Evaluation Model and Empirical Analysis [J] Tourism Tribune, 2013,28(9): 121-128.

[4] Lv Ning. The Connotation and Practice of Leisure City [J]. Economic Herald, 2011(2): 52-53.

[5] Wang Xuefeng. Studies on the Characteristic and Construct Approaches of Leisure City-A Case Study of Hangzhou City [D]. Shandong Normal University, Master's Dissertation, 2003

[6] Shan Yuanyuan. On Index System of Leisure City [D]. Zhejiang University, Master's Dissertation, 2005:20-21.

[7] Xu Minghong. On the Leisure Construction of City Space and Time [J] Zhejiang Social Sciences, 2006(2): 103-108.

[8] Wei Xiaoan, Li Ying. Urban-based Leisure Activities and Leisure City [J]. Tourism Tribune, 2007,22(10): 71-76.

[9] Ren Ci. On Evaluation Index System of Chinese Leisure City [D] Shanghai Normal University, Master's Dissertation, 2015: 16-21.

[10] Lv Ning. Study on the Index System of Evaluating Leisure City Based on CLI [J]. Journal of Capital University of Economics and Business, 2011(6): 77-85

[11] Lou Jiajun, Li Limei. Study on Chinese City Leisure [M]. Shanghai: Shanghai Jiao Tong University Press, 2018: 9-17.

[12] Zheng Shenghua, Liu Jialong. Research on the Evaluation Index Systems of the Urban Leisure Development [J]. Studies in Dialectics of Nature, 2006, 22(3):96-101.

[13] Cao Xinxiang, Miao Changhong, Chen Yuying. Study on the Index System to Evaluate Leisure City and Its Application [J]. Geographical Research, 2010, 29(9):1695-1705.

[14] Li Yuejun. On the Evaluation of City Leisure Life Suitability - A Case Study of Linhai in Zhejiang Province [J]. Journal of Tanzhou University, 2007(4):22-25.

[15] Wang Xiaoli, Wang Xuefeng. Analysis on the Qualification of Domestic Cities Constructing Leisure City [J]. Resource Development \& Market, 2007, 23(2):122-124.

[16] Chen Min. On Leisure City Evaluation Standard Based on Leisure Science [J]. Social Scientist, 2010(3): 89-92.

[17] Liang Feng, Zhou Yongbo, Wu Yaoyu. On Index System of City Leisure Development Level [J]. Journal of Wuxi Vocational Institute of Commerce, 2013, 13(2): 12-16.

[18] Liu Xinrong. Comparative Study of Leisure Economic Competitivenes in Central China [J]. Academic Journal of Zhongzhou, 2007, (2): 41-44. 
[19] Ouyang Xinhui, Chen Jianshu. The Index System and Model of Leisure Economic Competitiveness [J]. Statistics \& Decision, 2008(9): 153-154.

[20] Lu Yong. Construction of Evaluation Index System of Leisure Economic Competitiveness and Calculation of Regional Differences [J]. Statistics \& Decision, 2013 (5): 38-40.

[21] Peng Weixiang, Li Yue. The Leisure Economy Competitiveness Evaluation Based on the Factor Analysis [J]. Statistics \& Decision, 2013 (17): 64-66.

[22] Fang Shimin, He Yalan, Ning Zhidan. Research on Leisure Cities' Characteristics in China from the Perspective of Leisure Economy
Competitiveness [J]. Journal of Hunan University of Finance and Economics, 2016, 32(161): 141-146.

[23] Lv Ning. On the Development of Leisure Cities in China Based on City Leisure Index [D]. Minzu University of China, Doctor's Dissertation, 2009: 175-227.

[24] Wang Nan. Study on the Evaluation of Recreationalization in China, Japan, Singapore, Korea [D]. East China Normal University, Master's Dissertation 2016: 43-78. 